\title{
Variation of stress intensity factor through the thickness of plate
}

\begin{abstract}
Stress intensity factor (SIF) is one of the most important parameters in fracture mechanics. Therefore there is essential request on investigation of the behavior of SIF. Due to extensive and practical usage of plate structures in components, hence the behavior of SIF through the thickness of plate has been done. The three dimensional (3D) plate has simulated in ABAQUS finite element software. Crack tip has been meshed by 20 quarter node elements. The results presented that the SIF in free surfaces of plate had minimum value and variation of SIFs approximately was constant through the thickness of plate except on free surface.
\end{abstract}

Keyword: Stress intensity factor; Plate structure 